\title{
LOS EMERGENTES DEL SUR ANTE LA GOBERNANZA MUNDIAL DE LA AYUDA AL DESARROLLO: ESTRATEGIAS REFORMADORAS, RIVALIDADES Y TENTATIVAS
}

ISALINE BERGAMASCHI

Folashadé Soulé-KoHndou

LAS FILOSOFÍAS Y LÓGICAS de la ayuda oficial al desarrollo (AOD) evolucionan sin cesar al ritmo de los paradigmas y de los sucesos. ${ }^{1}$ Así, hay rivalidades que surgen y persisten entre los diferentes actores institucionales que evolucionan en un ambiente normativo en competencia. En el transcurso de la década de 2000, la recomposición de la gobernanza mundial ${ }^{2}$ de la AOD se agudizó con el

${ }^{1}$ Por ayuda oficial al desarrollo se entiende las transferencias que aprueba el Norte para el desarrollo de los PED. Para que sea considerado como AOD, un gasto debe cumplir cuatro condiciones: provenir de un organismo público (o de organismos que actúan en nombre de organismos públicos), beneficiar "a un país o territorio en desarrollo", que su intención sea el desarrollo de ese país o territorio, y estar acompañado de condiciones financieras favorables. Incluye, en principio, las operaciones de mantenimiento de la paz, las operaciones militares y policiales, y la investigación que no concierna directamente a los PED. Olivier Chamoz y Jean-Michel Severino, L'aide publique au développement, París, La Découverte, 2007, pp. 7-10; y Jean-Jacques Gabas, "L'économie politique de la coopération pour le développement”, Economies et Sociétés, vol. 8, núm. 35, 2000, pp. 65-86.

${ }^{2}$ Aquí adoptamos las definiciones clásicas del término "gobernanza" en la disciplina de las relaciones internacionales. James Rosenau define la gobernanza como la gestión de las interdependencias en ausencia de una autoridad central. Según Hedley Bull, el objetivo de la gobernanza global es establecer un conjunto de normas y reglas con el fin de alcanzar metas comunes. Véase James Rosenau (comp.), Governance without Government: Order and Change in World Politics, Cambridge, Cambridge University Press, 1992; y Hedley Bull, The Anarchical 
papel cada vez más presente de los donantes "emergentes", como China, la India o Brasil. La renovación de su política de cooperación ${ }^{3}$ refleja una evolución profunda de la economía política internacional y altera las categorías de "Norte" y "Sur", ${ }^{4}$ lo que lleva al "descentramiento del campo de desarrollo con respecto a los actores y prácticas que se consideran legítimos". ${ }^{5}$ El estatus doble de donador y beneficiario de dichos países ${ }^{6}$ cuestiona una dicotomía que está en la base del sistema de ayuda al desarrollo, cuyas raíces (financieras, institucionales, ideológicas y políticas) por lo común se encuentran en la situación (post) colonial. $^{7}$ Con el recrudecimiento de la cooperación Sur-Sur (css), que inició con el Movimiento de los No Alineados y de la conferencia de Bandung en 1955, y que ideó el componente de la gobernanza de la "cooperación para

Society: A Study of Order in World Politics, Nueva York, Columbia University Press, 1977 , p. 335.

${ }^{3}$ John Ruggie define la cooperación internacional como un "conjunto de anticipaciones comunes, de reglas y regulaciones, de planes, de acuerdos y de compromisos que acepta un grupo de países". Véase John Ruggie, "International Responses to Technology and Trends", International Organization, vol. 3, núm. 29, 1975 , pp. 557-583. Keohane y Nye la definen también como un conjunto de "normas, reglas y procedimientos que gobiernan la interdependencia en los diferentes ámbitos”. Robert Keohane y Joseph Nye, Power and Interdependence, Nueva York, Longman, 2011, p. 334. Para otras definiciones teóricas sobre la cooperación, véase Robert Axelrod, Donnant-Donnant. Théorie du comportement coopératif, París, Odile Jacob, 1992, p. 234; Robert Axelrod, The Evolution of Cooperation, Nueva York, Basic Books, 1984, p. 3.

${ }^{4}$ Rosalind Eyben y Laura Savage, "Emerging and Submerging Powers: Imagined Geographies in the Nueva Development Partnership at the Busan Fourth High Level Forum”, The Journal of Development Studies, vol. 49, núm. 4, 2013, pp. 457-469.

${ }^{5}$ Paulo Esteves y Manaíra Assunção, "South-South Cooperation and the Battlefield of International Development: between the oECD and the UN", Third World Quarterly, vol. 35, núm. 10, 2014, pp. 1775-1790.

${ }^{6}$ Hay que señalar que los emergentes rechazan los términos de "financiador", "donante" o incluso "ayuda"; su atributo preferido es "socio" o incluso "cooperación”.

${ }^{7}$ Gilbert Rist, The History of Development: From Western Origins to Global Faith, Nueva York, Zed Books, 2002, p. 286; y Kothari Uma, "From Colonial Administration to Development Studies: A Post-Colonial Critique of the History of Development Studies", en Kothari Uma (comp.), A Radical History of Development Studies: Individuals, Institutions and Ideologies, Nueva York, Zed Books, 2005, pp. 47-66. 
el desarrollo" en el plan de acción de Buenos Aires, ${ }^{8}$ la arquitectura tradicional de la ayuda está "en vías de ser reemplazada por un paisaje más diverso y complejo, que se caracteriza por tener nuevos actores y prácticas". 9

Este artículo parte de un enfoque empirista, basado en entrevistas e investigaciones de campo, y propone estudiar el papel de los países del Sur llamados "emergentes" 10 en la arquitectura y la reforma de la gobernanza mundial de la ayuda. En el marco de este artículo, entendemos por "emergentes del Sur" las potencias regionales (Brasil, la India, China y Sudáfrica), cuya acción diplomática trasciende la esfera subregional y muestra la afirmación y el dinamismo internacionales. El artículo compara sus acciones y estrategias en el Comité de Ayuda al Desarrollo (CAD) de la Organización para la Cooperación y el Desarrollo Económicos (OCDE) y del sistema de las Naciones Unidas, mediante el fomento de la css en el marco del Programa de las Naciones Unidas para el Desarrollo (PNUD). Ambas instituciones se sitúan en el centro de la gobernanza multilateral de la AOD y constituyen los dos "espacios de lucha en los que se redefinen las fronteras del campo del desarrollo internacional". ${ }^{11}$ Sus diferencias en materia de composición (la ocDE es una organización multilateral que excluye a los países en vía de desarrollo del mando y proceso de toma de decisiones) dejan ver el contraste entre las estrategias de involucramiento de los emergentes, para las que la eficacia y la legitimidad son cuestiones esenciales.

${ }^{8}$ La importancia de la cooperación entre países en desarrollo, sin embargo, ya se reconoció en la Asamblea General en la Resolución 32/183 de diciembre de 1977, que enuncia los objetivos de base de esta cooperación y designa el fortalecimiento de las capacidades entre países en desarrollo como medio para encontrar soluciones a sus desafíos sociales mutuos. "The Buenos Aires Plan of Action”, United Nations Special Unit for TCDC, 12 de septiembre de 1978.

${ }^{9}$ Charles Gore, "Introduction. The New Development Cooperation - Landscape: Actors, Approaches, Architecture”, Journal of International Development, vol. 25, núm. 6, 2013, p. 770.

${ }^{10}$ No hay unanimidad sobre el lugar de Rusia en este grupo y su clasificación como potencia "emergente". Nosotros decidimos excluirlo de nuestra categorización. Véase Christophe Jaffrelot (comp.), L'enjeu mondial. Les pays émergents, París, Presses de Sciences Po, 2008, pp. 147-162.

${ }^{11}$ Paulo Esteves y Manaíra Assunção, op. cit. 
Este artículo muestra que las potencias emergentes del Sur participan en la fragmentación de la gobernanza mundial de la ayuda mediante la movilización de sus estrategias reformistas deliberadas en el seno de las instituciones multilaterales. A pesar de la debilidad de los flujos de ayuda multilateral establecidos, ${ }^{12}$ sus estrategias reformadoras se vuelven un medio para determinar y legitimar la agenda Sur-Sur de la cooperación para el desarrollo, conque pueden posicionarse como sus principales promotores.

Tras una presentación de los actores y del campo de la gobernanza mundial de ayuda y sus reconfiguraciones recientes, el artículo analiza las estrategias reformadoras de los países emergentes frente a las instancias multilaterales de estudio. Finalmente, describe cómo el CAD y las agencias de la ONU se van adaptando progresiva y estratégicamente al alza de los cooperantes no tradicionales.

\section{LA GOBERNANZA MUNDIAL DE LA AYUDA: \\ UNA ARQUITECTURA FRAGMENTADA}

La gobernanza mundial de la ayuda al desarrollo es bastante amplia, múltiple, fragmentada y en plena recomposición; la atraviesan rivalidades institucionales que también reflejan un conjunto de competencia y desacuerdo entre Norte y Sur.

\subsection{Un campo en ebullición, una producción normativa competitiva}

La gobernanza de la AOD está fragmentada; la dirigen tres grupos principales: las instituciones financieras internacionales (IFI), es

12 Como ejemplo, Brasil aumenta su contribución a los fondos multilaterales del Mercosur (FOCEM) de 1.9 millones de reales en 2005 a 133.9 millones de reales en 2010, mientras que la ayuda multilateral que dedica a las Naciones Unidas no representa más que el $3 \%$ de la APD entre 2005 y 2009. Los detalles de estas contribuciones se precisan en el informe IPEA/ABC, "Brazilian Cooperation for International Development: 2005-2009”, 2011 (Informe), p. 36; y Iara Costa Leite et al., "Brazil's Engagement in International Development Cooperation: The State of the Debate”, IDs, 2014 (Evidence Report núm. 59), pp. 36-37. 
decir el Banco Mundial y el Fondo Monetario Internacional (FMI); las instituciones de la ONU; y el CAD de la OCDE. En cuanto a la gobernanza de la cooperación Sur-Sur, encuentra su marco normativo en las instituciones de la ONU y no dispone de un marco reglamentario como el del CAD, que regula la ayuda pública para el desarrollo de los financiadores tradicionales.

Su misión, papel, contribuciones, sus posicionamientos y los intercambios entre estos actores se ilustran aquí en el contexto del gran movimiento de reforma de la ayuda que inició en la década de 1990.

Las IFI se crearon para asegurar la estabilidad financiera y movilizar los recursos necesarios para la reconstrucción tras la Segunda Guerra Mundial. El Banco Mundial se fue imponiendo como el principal canal multilateral de financiamiento para el desarrollo, mientras que el FMI vigila la estabilidad macroeconómica. Estas instituciones son clave para el análisis, las recomendaciones y las condiciones que conducen a la implementación de los programas de ajuste estructural (PAS) en los países en desarrollo (PED) durante los años ochenta (América Latina) y sobre todo durante los noventa (África).

Tras el fin de la Guerra Fría, algunos estudios muestran que la ayuda no ha permitido mejorar de forma significativa el desempeño económico (en especial el crecimiento) ni los indicadores sociales de los países pobres, principalmente en África subsahariana. ${ }^{13}$ En la segunda mitad de la década de 1990, el Banco Mundial queda "en estado de sitio", ${ }^{14}$ sin poder "involucrarse en la vía de una renovación fundamental" 15 y reconduce el movimiento a partir de 1995, bajo el impulso de su nuevo director, James Wolfensohn, ${ }^{16} \mathrm{y}$ de su principal economista y vicepresidente, Joseph Stiglitz.

${ }^{13}$ Estas conclusiones se ponen en evidencia en 1987 en el Fondo de las Naciones Unidas para la Infancia (Unicef) en un informe impactante titulado $A d$ justment With a Human Face.

${ }^{14}$ Ruth Kagia (comp.), Balancing the Development Agenda: The Transformation of the World Bank under James D. Wolfensohn (1995-2002), Washington, D. C., The World Bank, 2005, p. 2.

${ }^{15}$ Patrice Dufour, "La Banque Mondiale et la lutte contre la pauvreté", Les Cahiers Français, núm. 5-6, 2001, p. 57.

${ }^{16} \mathrm{Si}$ el FMI y el Banco Mundial se sometieran a análisis, es el Banco, tradicio- 
En el año 2000, la lucha contra la pobreza se convierte en objetivo del Banco Mundial tras la publicación del informe Attacking Poverty. Este cambio está directamente ligado a una iniciativa de las Naciones Unidas: los Objetivos del Milenio para el Desarrollo (OMD), que adoptaron 189 naciones y firmaron 147 jefes de Estado durante la Cumbre del Milenio de septiembre de $2000 .{ }^{17}$ Su objetivo es reducir a la mitad, de ahí a 2015, la cantidad de habitantes de los PED que viven en la miseria. Ocho objetivos comprometen a donantes y países pobres. ${ }^{18}$ El llamado de la onU mueve y conmueve: la persecución de los omD implica el aumento de los recursos destinados a la ayuda. ${ }^{19}$

El CAD de la OCDE establece el último pilar de la reforma anunciada, con un posicionamiento específico en el campo de la ayuda. Creado en enero de 1960, el CAD se compone casi exclusivamente de los donadores tradicionales, los del Norte, mayoritariamente europeos, y agrupa a los principales financiadores tradicionales de la AOD. ${ }^{20}$ Además, el CAD es un foro de cooperación y no una agencia ejecutiva. La organización no tiene vocación operacional: no financia ni implementa proyectos ni programas de desarrollo. Su poder es esencialmente normativo: se apoya en la experiencia, la concertación, la producción y el intercambio de información (datos sobre la AOD, estadísticas, estudios), e incluso en la presión de sus pares

nalmente más abierto al exterior que el FMI, el que más escuchó e integró las críticas. Ngaire Woods, The Globalizers: The IMF, the World Bank and their Borrowers, Ithaca, Cornell University Press, 2006, p. 8.

${ }^{17}$ Programa de las Naciones Unidas para el Desarrollo (PNUD), "Objetivos del Milenio para el Desarrollo (OMD)”. http://www.undp.org/french/mdg/, consultado el 10 de octubre de 2015.

${ }^{18}$ Los objetivos son: reducir la extrema pobreza y el hambre, asegurar la educación primaria para todos, promover la igualdad de géneros y la autonomización de las mujeres, reducir la mortalidad infantil, mejorar la salud materna, combatir el VIH/sIDA, el paludismo y otras enfermedades, preservar el ambiente, establecer una alianza mundial para el desarrollo. Estos objetivos derivan a su vez en 21 puntos cuantificables, medidos por 60 indicadores.

${ }^{19}$ Ngaire Woods, op. cit., p. 171.

${ }^{20}$ Véase la lista de miembros del CAD: http://www.oecd.org/dac/dacmem bers.htm, consultado el 15 de octubre de 2014. 
sobre la AOD (y no, como el Banco Mundial, sobre los objetivos del desarrollo).

En el transcurso de la última década, el comité se concentró y ubicó como creador de normas sobre las cuestiones de la eficacia de la AOD (y no, como el Banco Mundial, sobre las cuestiones del desarrollo como tales). La Declaración de París (DP), adoptada en 2005, pretende racionalizar los procesos y modalidades de implementación de la ayuda apelando a las "buenas prácticas". La DP fue firmada por sesenta PED, treinta países donantes bilaterales y treinta agencias multilaterales de cooperación en París en 2005. Con la "Agenda de París", el CAD regresa a escena tras años de poca actividad e influencia. ${ }^{21}$ A la Declaración siguieron una cumbre internacional de alto nivel organizada en Accra (Ghana) en 2008 y el $4^{\circ}$ Foro de Alto Nivel en Busan (Corea del Sur) en 2011 para el Desarrollo, no sólo para la ayuda, y se creó la "Alianza Global para la Cooperación Eficaz al Desarrollo”. La primera reunión de Alto Nivel de la Alianza Global se dio en México, en abril de 2014.

En paralelo con los financiadores tradicionales, los países del Sur, y principalmente los emergentes, participan en esta competencia normativa en torno a la AOD. El aporte de estos actores se manifiesta esencialmente a través del fomento de la cooperación Sur-Sur, es decir entre países en desarrollo (PED) en la ONU.

\subsection{La cooperación Sur-Sur: especificidades e instancias de decisión}

La css encuentra su principal marco de gobernanza en el plan de acción que surge de la conferencia de Buenos Aires de 1978 sobre

${ }^{21}$ Discusión con Nicolas Bouchet con base en las entrevistas que realizó al CAD de la OCDE. Su tesis, realizada en el IEP de Burdeos, trata el surgimiento de la noción de "Estado frágil" en la ocDE desde los años noventa, a favor de un acercamiento entre las agendas de "desarrollo" y de "seguridad". Nicolas Bouchet, "La négociation multilatérale de l'aide aux Etats fragiles: constructions d'agendas et stratégies d'influence au Comité d'aide au développement de l'OCDE", tesis de doctorado, Ciencia Política, IEP de Burdeos, 2011. 
la cooperación técnica entre PED $^{22}$ y del documento final de Nairobi sobre la css, de 2009. ${ }^{23}$

La agenda Sur-Sur de desarrollo se presenta como autónoma, independiente, pero complementaria a la del Norte. El documento final de Nairobi menciona que "la cooperación Sur-Sur no debe verse como una forma de ayuda oficial al desarrollo ${ }^{24}[\ldots]$ no debería sustituir la cooperación Norte-Sur [...] sino complementarla" 25 y que "la cooperación Sur-Sur y el programa de acción referido deben definirlos los países del Sur y deberían seguir estando regidos por los principios de la soberanía nacional, la apropiación y la independencia nacionales, la igualdad, la ausencia de condiciones, la no injerencia en los asuntos internos y el interés mutuo". ${ }^{26}$

La css no dispone de una estructura única de gobernanza. Se da esencialmente mediante procesos de la onU, como la conferencia de alto nivel sobre la cooperación Sur-Sur o la Cumbre del Sur que organizó el G77, a cuyo secretario ejecutivo coordinan las Naciones Unidas. No todos los países del Sur y miembros del G77 se someten a los principios que dictan las instituciones de la ONU, lo que demuestra el carácter no vinculante de sus normas y la autonomía que buscan ciertos países del Sur. Este es principalmente el caso de México y de Chile, también miembros del CAD de la ocDE. A nivel institucional, la Oficina de las Naciones Unidas para la Cooperación Sur-Sur ${ }^{27}$ media entre agencias; la Asamblea General

22 "The Buenos Aires Plan of Action", United Nations Special Unit for TCDC, 12 de septiembre de 1978.

${ }^{23}$ A/RES/64/222, Documento final de Nairobi adoptado por la Conferencia de Alto Nivel de las Naciones Unidas sobre la Cooperación Sur-Sur, §18, 2009.

${ }^{24}$ A/RES/64/222, op. cit.

${ }^{25}$ A/RES/64/222, op. cit., §14. La declaración de Busan intenta superar la tensión e integrar ambos tipos de cooperación, Norte-Sur y Sur-Sur, como complementarios (art. 8), Busan Partnership for Effective Development Cooperation, $4^{\circ}$ Foro de Alto Nivel sobre Efectividad de la Ayuda, 29 de noviembre-1 diciembre de 2011.

${ }^{26}$ A/RES/64/222, §11, op.cit.

${ }^{27}$ Por sus siglas en inglés: UNOssc, antes SU-ssc. Oficina de las Naciones Unidas para la Cooperación Sur-Sur. Antes de 2012 se llamaba Unidad Especial para la Cooperación Sur-Sur (su-ssc). El fomento de "unidad" en una "oficina" sigue a la conferencia de alto nivel sobre la cooperación Sur-Sur de Nueva York en mayo de 2012. 
de las Naciones Unidas le otorgó esa función, y la Oficina responde sobre todo al G77.

Frente a esta gobernanza múltiple de la AOD, las tensiones Norte-Sur se concentran esencialmente en el papel que deben jugar el CAD ${ }^{28}$ y su agenda de eficacia de la ayuda. ${ }^{29}$ La principal crítica de los emergentes es su ausencia de participación en la elaboración de las reglas y referencias del CAD. El CAD llama con regularidad a respetar el principio de armonización de la ayuda, ${ }^{30} \mathrm{y}$ alienta a los PED comprometidos con la cSs a servirse de los principios de la DP como punto de referencia para otorgar la AOD. ${ }^{31}$ Las potencias emergentes como China, Brasil, la India y Sudáfrica muy a menudo rechazan el calificativo de donantes ${ }^{32}$ y rechazan cualquier mención al CAD, a la Declaración de París e incluso a la de Busan, pues consideran que dichos acuerdos son exclusivos y están esencialmente guiados por los intereses del CAD.

Por lo tanto, la gobernanza multilateral de la AOD se fragmentó, con varios procesos paralelos de gobernanza puestos en marcha por separado. La India, Brasil, Sudáfrica y China abogan por la primacía de la onU, pues es incluyente, representativa, y por lo tanto legítima. ${ }^{33}$ Algunos Estados del Sur estiman que esta doble

${ }^{28}$ En diciembre de 2013, el CAD de la OCDE reagrupaba 29 miembros, la mayoría países desarrollados, y una organización regional, la Unión Europea.

${ }^{29}$ Sobre todo las declaraciones de París y de Busan.

${ }^{30}$ Armonización: Los países donadores se orquestan, simplifican sus procedimientos y comparten la información para evitar que sus esfuerzos no sean dobles (§32). Declaración de París sobre la Eficacia de la Ayuda en el Desarrollo, 2005.

${ }^{31}$ Declaración de París sobre la Eficacia de la Ayuda en el Desarrollo, 2005, art. 19a.

${ }^{32}$ En la retórica de los dirigentes de las potencias emergentes no se acepta la apelación de "donantes" o "financiadores", prefieren el término más neutro de "socios en el desarrollo" para que no se los considere aportadores tradicionales del CAD y para no caer, aunque sólo sea simbólicamente, en una lógica Norte-Sur. Fahimul Quadir, "Rising Donors and the New Narrative of 'South-South' Cooperation: What Prospects for Changing the Landscape of Development Assistance Programs?”, Third World Quarterly, vol. 34, núm. 2, 2013, pp. 321-338.

${ }^{33}$ Joren Verschaeve, "Is the Development Assistance Committee still Calling the Tune in International Development? A Comparative Analysis of the Legitimacy of the OECD-DAC and the UN-DCF", Presentación durante la 8th Pan-European Conference on International Relations, Varsovia,18-21 de septiembre de 2013. 
gobernanza, costosa y cronófaga, atenta contra la eficacia de la ayuda. Consideran también que las Naciones Unidas siguen siendo el único organismo capaz de reunir los diversos intereses de sus miembros, como sucedió con la puesta en marcha de los OMD. ${ }^{34}$

Los Estados emergentes abogan regularmente por el fomento de la css a nivel bilateral, regional y subregional, y por la aplicación de los referentes del desarrollo tal y como se promovieron desde la conferencia de Buenos Aires de 1978, que la declaración de Nairobi de 2009 recuerda. Así, las instituciones de la onU se vuelven socios selectos para acompañar su surgimiento como nuevos financiadores en la AOD frente a países menos adelantados (PMA).

Por lo tanto, las estrategias de los emergentes del Sur oscilan entre exigir reformas (en el PNUD) y cuestionar con más profundidad la legitimidad de las prácticas tradicionales de la AOD y de los mecanismos de gobernanza multilateral (el caso del CAD en la OCDE).

\section{LAS ESTRATEGIAS REFORMISTAS Y COMPETITIVAS DE LOS EMERGENTES DEL SUR}

Las estrategias y prácticas de los emergentes en las instancias multilaterales difieren ampliamente: al tiempo que deslegitiman ${ }^{35}$ sistemáticamente las normas y productos del CAD, intentan reformar las formas de operación de ciertas agencias de la ONU, como el PNUD.

Desde 1974, la agenda internacional de fomento de la css de los países en desarrollo se hace en conjunto con el PNUD, cuyo plan prevé que la institución consiga fondos para impulsar la ejecución de los programas. ${ }^{36}$ De entrada, se pretende que el PNUD

34 Glennie Jonathan, "The UN Can Represent the Interests of Poorer Countries Better than the oEcD”, Povertymatters blog, The Guardian, 23 de mayo de 2011.

35 "Las prácticas de deslegitimación son resultado de intentos de los miembros del sistema que, por un periodo largo, no encuentran un flujo satisfactorio de ventajas asociado al desempeño del sistema". Michel Dobry, Sociologie des crises politiques: la dynamique des mobilisations multisectorielles, París, Presses de Sciences Po, 2009.

36 "Operationalization of South-South and Triangular Cooperation within UNDP", en Evaluation of UNDP Contribution to South-South and Triangular Cooperation (2008-2011), UNDP, 2013 (Informe). 
adopte un papel de liderazgo y facilitador entre los PED y las agencias ejecutivas de la organización. En 1997 se formuló un plan trienal de apoyo para la css que enumera un conjunto de enfoques transversales. ${ }^{37}$

Sin embargo, los emergentes han hecho críticas recurrentes y crecientes al PNUD a partir de 2003. La India le reprocha una visión y gestión verticales, "Norte-Sur", del desarrollo y de los proyectos que dejan poco margen a los países beneficiarios. ${ }^{38}$ Según las autoridades del país, "la onU refleja esencialmente las prioridades e intereses de los donantes del Norte", ${ }^{39}$ poco adaptados y adecuados para la implementación de la css. ${ }^{40}$

Por lo tanto, las estrategias reformadoras de los emergentes se ponen en marcha mediante un conjunto de prácticas que consisten en deslegitimar las formas de operación y el desempeño del PNUD, pero no la institución de la onU como tal, pues su plataforma es un espacio de legitimación para las potencias emergentes que les permite hacer más visibles sus acciones.

Concretamente, las prácticas reformadoras que introdujeron los países emergentes en el sistema de la onU se ilustran sobre todo con el caso de los fondos IBSA, creados en 2004 por la India, Brasil y Sudáfrica, y coordinados por el PNUD, para financiar proyectos en forma de donaciones a los PMA. ${ }^{41}$

${ }^{37}$ UNDP Strategic Plan 2008-2011, 2008, pp. 22-23.

38 Entrevista con un funcionario internacional de la unidad especial para la cooperación Sur-Sur, Nueva York, 3 de noviembre de 2001.

39 "The UN is failing to lead on Ssc because it reflects the priorities of northern donors", extracto de la declaración de la delegación india, UN-DCF 28 de junio de 2010, Misión Permanente de la India ante las Naciones Unidas: https:/ / www.pminewyork.org/, consultado el 9 de octubre de 2014.

40 Evaluation of UNDP Contribution to South-South and Triangular Cooperation (2008-2011), UNDP, 2013 (Informe), p. 41.

${ }^{41} \mathrm{El}$ fondo IBSA constituye el tercer pilar de cooperación del foro IndiaBrasil-Sudáfrica, creado en 2003 en Brasilia. El objetivo del fondo, compuesto por un presupuesto anual de tres millones de dólares y financiado a partes iguales entre los Estados miembros del foro IBSA (un millón por Estado miembro), es financiar microproyectos de desarrollo en los PMA de Asia, África y Sudamérica. En 2013 el fondo financió doce proyectos de desarrollo multisectoriales. Véase el anexo 1 . 
2.1. El caso de los fondos Sur-Sur, India-Brasil-Sudáfrica: la reforma mediante la deslegitimación de las formas de operación tradicionales

La decisión de destinar la gestión de los fondos IBSA a la entonces Unidad Especial de las Naciones Unidas para la Cooperación SurSur de la onU (sU-SSC) no fue automática y sufrió varios cambios. Los fondos disponibles para los proyectos de desarrollo no encuentran agencia para su ejecución. En 2004, se establece poco a poco la Agencia Brasileña de Cooperación $(\mathrm{ABC})$, que aún no tiene las capacidades técnicas ni humanas necesarias; Sudáfrica no dispone de una agencia de desarrollo; ${ }^{42}$ y la agencia india de cooperación técnica (ITEC) dirige la mayoría de sus proyectos a la región asiática. ${ }^{43}$ Constantemente se evoca la idea de crear un mecanismo de coordinación propio al IBSA, pero falla cada vez por cuestiones de costos y de falta de experiencia. ${ }^{44}$

$\mathrm{Al}$ principio no resulta fácil asociar al PNUD. Las agencias ejecutivas del programa de la onU y los funcionarios en turno, a cargo de la coordinación de los fondos multilaterales, se rehúsan a financiar pequeños proyectos y estiman que es necesario un equilibrio entre los financiamientos asignados y el tamaño del proyecto. En efecto, en comparación con otros fondos de desarrollo que administra el PNUD, el débil presupuesto anual de los fondos IBSA ascendía a tres millones de dólares. ${ }^{45}$ Sin embargo, la institución acepta su creación.

42 Esta situación evoluciona con la creación de la Agencia de Desarrollo Internacional Sudafricana (ADIS) en 2007, que después se convierte en la Alianza Sudafricana para el Desarrollo, cuya creación en 2013 está en curso. Alessandro Besharati Neissan, "South African Development Partnership Agency (SADPA): Strategic Aid or Development Packages for Africa?”, South African Institute of International Affairs, 2013 (Research Report núm. 12); y Brendan Vickers, "Towards a New Aid Paradigm: South Africa as African Development Partner", Cambridge Review of International Affairs, vol. 25, núm. 4, 2012, pp. 535-556.

${ }^{43}$ Nils-Sjard Schulz, "Development Agencies in BRICS and Beyond-Experiences and Next Steps", BRICs Policy Center, 2013 (BRICs Monitor).

${ }^{44}$ Entrevista con un representante brasileño, Brasilia, 16 de abril de 2011.

45 Como comparación el fondo de las Naciones Unidas para la Cooperación Sur-Sur dispone de un presupuesto anual de quince millones en 2011. Entrevista con un representante brasileño, Brasilia, 16 de abril de 2011. 
La transferencia de los fondos IBSA a partir de 2006 hacia la su-ssc, que también administra el fondo especial de las Naciones Unidas para la Cooperación Sur-Sur, se vuelve entonces un medio para afirmar la orientación "Sur-Sur" del fondo IBSA: el "trust fund" IBSA, que coordina el PNUD, se vuelve un "fondo Sur-Sur" para la disminución del hambre y la lucha contra la pobreza. La SU-SSC lo administra y coordina; el PNUD financia y ejecuta sus proyectos. En 2004, las referencias iniciales del PNUD no hacen mención alguna de la dimensión Sur-Sur del fondo; tampoco figuran las referencias a la cooperación entre socios en desarrollo. Esta evolución semántica sirve sobre todo como medio para el IBSA y para Brasil, cuya orientación Sur-Sur en materia de política exterior con Luiz Inácio Lula da Silva es notoria, de promover la css y ubicarse como financiador emergente. ${ }^{46}$ También es una oportunidad política para mejorar las relaciones bilaterales de la India, Brasil y Sudáfrica con los PED, donde se implementan los proyectos que financia el IBSA. Entre 2003 y 2012, el fondo IBSA financia trece proyectos de desarrollo en otros países. En términos de repartición regional, cinco proyectos fueron para África, cuatro para Asia, tres para Medio Oriente y uno para Sudamérica y el Caribe. La mayoría se financian en la categoría de países menos adelantados $(74 \%)$ y el resto en países en desarrollo $(26 \%) .{ }^{47}$

Las oficinas del PNUD en los PED se asociaron como agencias ejecutivas de los proyectos que financia el fondo IBSA. Esta asociación es estratégica. La idea de hacer del fondo IBsA un fondo multilateral Sur-Sur que no financie proyectos más que en terceros países, y no en sus respectivos países, permite que los tres emergentes se presenten como actores que participan en el desarrollo de los países del Sur y, por lo tanto, como socios responsables. El marco multilateral les sirve como palanca de legitimación colectiva. La decisión de asociar a la organización multilateral también ofrece mayor credibilidad a la iniciativa del IBSA. En un contexto

${ }^{46}$ Folashadé Soulé-Kohndou, "Les clubs de puissances émergentes: fonctions objectives et usages stratégiques- le cas du forum de dialogue IBAs (Inde-Brésil-Afrique du Sud)", tesis de doctorado, Ciencia Política, Relaciones Internacionales, Instituto de Estudios Políticos de París, 2014.

${ }^{47}$ Anexo 1: proyectos financiados por el fondo IBSA. 
en que los emergentes van estableciendo poco a poco el marco institucional de sus agencias de desarrollo, y en que el fondo IBSA se ve como un laboratorio de cooperación trilateral, tales países esperan de la SU-SSC y del PNUD la formulación y ejecución de los proyectos a partir de referencias de la css para el desarrollo, y les brinda así los mecanismos y experiencia que les hacen falta. ${ }^{48}$

De esta forma, la onU se vuelve un actor imprescindible a nivel tanto técnico como político para promover la css a través del fondo IBSA. La decisión del PNUD se vuelve la solución por defecto, pues se trata de la agencia de la onu de ejecución de proyectos que dispone de una presencia y red de las más extendidas en este ámbito, con 166 oficinas de ejecución en todo el mundo. Pero la decisión también es política y obedece a estrategias reformistas. En su tránsito por el multilateralismo, los tres emergentes quieren que las instituciones multilaterales de la onU conduzcan la cooperación "de otra forma", sobre todo mediante una gestión más orientada hacia el desarrollo Sur-Sur.

La gestión intenta obedecer el principio "de apropiación", ${ }^{49}$ que en la administración del fondo IBSA se traduce por un proceso muy centralizado en los puntos focales (funcionarios de alto nivel en los ministerios de asuntos exteriores), y representantes diplomáticos permanentes de la India, Brasil y Sudáfrica ante Naciones Unidas. Estos últimos forman el "Consejo de Directores del Fondo IBSA", que asegura el control en todos los niveles.

Por una parte, los términos de referencia iniciales que acordaron el PNUD y el IBSA prevén un fondo abierto a contribuciones externas, como se afirma en su declaración durante la 58 sesión de la Asamblea General, ${ }^{50}$ que se coordina con las reglas y formas de operación de la administración de los fondos multilaterales y nacionales que estableció el PNUD. ${ }^{51}$ Sin embargo, el principio de apertura sigue siendo teórico: en la práctica, el IBSA no autoriza

${ }^{48}$ Entrevista con un representante brasileño, Brasilia, 16 de abril de 2011.

49 A/RES/64/222 - Nairobi outcome document of the high-level United Nations conference on South-South Cooperation.

${ }^{50}$ IBSA New York comunicado, 58 sesión de la Asamblea General de las Naciones Unidas, septiembre 2004,

${ }^{51}$ Anexo 1: proyectos financiados por el fondo IBSA. 
contribuciones externas, a pesar de las muestras de interés de varios Estados miembros de la onU, principalmente Japón. ${ }^{52}$ Así, el IBSA mantiene el control de fondo e impone su visión y sus reglas de administración a la institución de la onU.

La su-ssc entra muy tarde a la fase de selección del proyecto, y la toma de decisiones se limita esencialmente al país solicitante y a las instituciones del IBSA. A nivel del procedimiento de identificación, la SU-Ssc sólo se encarga de dar seguimiento a las demandas que recibe el consejo de directores del fondo ibsa.

La gestión diplomática del fondo se ejerce en la fase de formulación y ejecución del proyecto: la identificación de las capacidades y la experiencia durante la ejecución es responsabilidad de los gobiernos del IBSA. Por lo tanto, estos últimos se encargan de encontrar experiencia y capacidades locales en la India, Brasil y Sudáfrica. El consejo de directores del fondo IBSA supervisa ampliamente esta fase, en colaboración con los diplomáticos y representantes indios, brasileños o sudafricanos que se encuentren o tengan un cargo en el país beneficiario. En esta etapa, la su-ssc se encarga de reunir los informes de seguimiento que recibe la agencia local del PNUD en el terreno en que se realiza el proyecto. En la práctica, la supervisión se traduce en un seguimiento cercano de la evolución del proyecto y en cuatro reuniones anuales entre el consejo de directores y la su-ssc, mientras que las prácticas en vigor para los demás fondos no incluyen más que un envío anual del informe del PNUD. ${ }^{53}$

Este método de administración es específico del fondo IBSA y difiere de los de otros fondos multilaterales financiados por cooperantes tradicionales. En efecto, la identificación de los proyectos que financian estos últimos y que administran el PNUD y la su-sSc realzan de forma general la importancia de estas instituciones. Generalmente, en los proyectos que gestiona el PNUD, los países donantes le delegan casi por completo la selección, formulación, gestión financiera, elección de socios locales y la ejecución

${ }^{52}$ Entrevista con un representante indio, Nueva York, 16 de febrero de 2011.

${ }^{53}$ Entrevista con un funcionario internacional, Nueva York, 3 de noviembre de 2011 . 
del proyecto. ${ }^{54}$ Esta autonomía le permite a la organización desarrollar sus propias formas de operación y establecer prácticas y políticas que su burocracia estime adecuadas. ${ }^{55}$

Desde el punto de vista de los emergentes, el conjunto de métodos de administración del fondo iBsa pretende aplicar al pie de la letra los referentes de la cooperación Sur-Sur mediante la apropiación de los Estados del Sur desde la selección de los países beneficiarios del proyecto hasta su cierre. Al manejar así los mecanismos de gestión del proyecto y al quitarle al PNUD autoridad y autonomía, los representantes que administran el fondo iBsa adoptan una estrategia reformista que viene de la descentralización de la toma de decisiones y reduce ampliamente los márgenes de maniobra del PNUD, así como los de la SU-SSC en la gestión de los fondos multilaterales Sur-Sur. Estos mecanismos de gestión diplomática reflejan objetivos políticos y estratégicos, tanto en la selección de proyectos y el tipo de proyectos financiados, como en la elección de las capacidades y actores asociados en su ejecución.

Esta forma de gestión diplomática responde a una urgencia de visibilidad: las actividades que reciben apoyo financiero y técnico del fondo IBSA deben "atribuirse al fondo". ${ }^{56}$ La visibilidad simbólica es herramienta de legitimación y demuestra la necesidad de reconocimiento internacional propio de la diplomacia de las potencias emergentes ${ }^{57}$ en sus interacciones con los PMA, pero también con los funcionarios del PNUD y de la sU-ssc. Los premios internaciona$1 \mathrm{e}^{58} \mathrm{y}$ el realce en los medios nacionales e internacionales de la

${ }^{54}$ Entrevista con un funcionario internacional, Nueva York, 3 de noviembre de 2011.

${ }^{55}$ Michael Barnett y Martha Finnemore, Rules for the World - International Organizations in Global Politics, Ithaca, Cornell University Press, 2004, p. 5.

56 Anexo 1: proyectos financiados por el fondo IBSA.

57 Andrew Hurrell, "Hegemony, Liberalism and Global Order: What Space for Would-Be Great Powers?”, International Affairs, vol. 82, núm. 1, 2006, pp. 1-19.

${ }^{58}$ Entre 2004 y 2012, el fondo IBSA gana tres premios internacionales: el premio de la Alianza Sur-Sur en 2006 por el proyecto en Haití, el premio de los Objetivos del Milenio para el Desarrollo en 2010, y el premio de "Defensores de la cooperación Sur-Sur y triangular" en diciembre de 2012. La onU entrega los tres premios. El proyecto IBSA en Haití también fue uno de los doce finalistas para el 
acción colectiva del fondo IBSA les aseguran una visibilidad desproporcionada en relación con los montos financieros invertidos.

Las estrategias reformistas que usan los emergentes en las instituciones de la onU son, por lo tanto, deliberadas y puestas en marcha por estos actores con el fin de asentar su legitimidad y otorgar más importancia a la css en la arquitectura de la gobernanza mundial de la AOD. Estas estrategias también pasan por una deslegitimación de las normas del CAD de la OCDE.

\subsection{Los emergentes y la agenda de París: participación ambigua y deslegitimación sistemática del $C A D^{59}$}

Ante la multiplicación de los cooperantes, la apertura (outreach) es un objetivo cada vez más pesado en el CAD. En la década de 2000, los esfuerzos del CAD se orientaron hacia los beneficiarios de la ayuda (principalmente, países menos adelantados de Centroamérica y África subsahariana), antes de concentrarse prioritariamente en los donadores emergentes como los BRICs, en particular Brasil, la India, China y Sudáfrica. ${ }^{60}$ Aunque la declaración de París no mencione a los donantes emergentes, la Agenda de Acción de Accra de 2008 presenta la cooperación Sur-Sur como un "complemento útil para la cooperación Norte-Sur" e invita a los emergentes a adoptar los principios de eficacia de la ayuda. ${ }^{61}$

Tras su adopción, decenas de beneficiarios firmaron la Declaración de París, mismos que se asociaron y participaron activamente

World Challenge Contest en 2009, un premio copatrocinado por la cadena británica ввс, la revista estadounidense Newsweek y la petrolera Shell.

${ }^{59}$ Esta sección retoma ampliamente elementos presentes en Isaline Bergamaschi, "The DAC and the South: Strategies of Association and Participation", presentación durante el seminario Organisations Internationales, SciencesPo/CERI/ GRAM, París, 5 de junio de 2014.

${ }^{60}$ Gerardo Bracho Carpizo y Agustín Garcia-Lopez Loaeza, "México y el CAD de la ocDE: Una relación en construcción”, Revista Española de Desarrollo y Cooperación, núm. 28, 2011, p. 67.

${ }^{61}$ Paolo de Renzio y Jurek Seifert, "South-South Cooperation and the Future of Development Assistance: Mapping Actors and Options”, Third World Quarterly, vol. 35, núm. 10, 2014, pp. 1860-1875. 
en su implementación y seguimiento. El Grupo de Trabajo sobre la Eficacia de la Ayuda (WP-EFF), creado en 2003, incluía países beneficiarios, donadores emergentes, organizaciones de la sociedad civil, fondos mundiales, sector privado y parlamentarios. El número de participantes pasó de una treintena en 2003 a más de 80 en Accra en 2008, debido principalmente a la participación de delegaciones del Sur, que estaban representadas por un copresidente y formaron parte del proceso de la toma de decisión en calidad de sherpas (caso de Bangladesh, Ruanda, Sudáfrica, Mali, Timor Oriental, China, México y Honduras) para la preparación del $4^{\circ}$ Foro de Alto Nivel en Busan (Corea del Sur) en 2001. De forma voluntaria, esos países podían participar en las reuniones del Grupo de Trabajo en París sin someterse al procedimiento oficial de adhesión o participación al CAD, establecer o contribuir en equipos de tareas o bloques temáticos ${ }^{62}$ y participar en el Partner country causus, un foro informal donde, desde 2008, los países beneficiarios han podido intercambiar experiencias y definir posiciones comunes en las negociaciones.

Mientras que los países beneficiarios han apreciado y ocupado los espacios que abrió el CAD para promover sus prioridades (utilización de los sistemas y procedimientos nacionales en la implementación, desvinculación y previsibilidad de de la ayuda, etc.), las posturas de los emergentes han sido esencialmente deslegitimadoras -más que reformadoras- frente a la agenda de la eficacia de la ayuda. Si bien no se puede hablar de una estrategia orquestada de los emergentes, sí se puede distinguir que sus posturas individuales comparten cierta cantidad de puntos en común. Los donantes emergentes también han participado de forma errática, limitada y ambigua en los trabajos y discusiones, y rechazado todo compromiso firme y definitivo con los principios y objetivos de la agenda de eficacia. De forma general, se han comportado como socios reticentes del CAD. Brasil, China y la India en particular no

${ }^{62}$ Los grupos de tareas y bloques temáticos son iniciativas del tercero y cuarto foros de Alto Nivel. Permitieron que los socios y organizaciones se unieran bajo asuntos urgentes de desarrollo y concentraran esfuerzos para mayor progreso en estas áreas. 
han dejado de cuestionar la legitimidad del Comité en la gobernanza mundial de la ayuda. ${ }^{63}$

En París, los representantes de la embajada de China en Francia asistieron por ejemplo a algunas reuniones del Grupo de Trabajo, pero hicieron contribuciones poco constructivas: exigieron la supresión simple y llana de todos los párrafos que hacían referencia a la transparencia de la ayuda. ${ }^{64}$ Sudáfrica jugó un papel positivo e intentó convencer a la India y China de implicarse más, en vano. Brasil, la India y China no se unieron al Partner country causus, aunque se los invitó. ${ }^{65} \mathrm{Al}$ contrario de Brasil, China aceptó participar en el sistema de los sherpas. México trabajó para facilitar el diálogo entre cooperantes tradicionales y emergentes, al tiempo que solicitaba que estos últimos ejercieran "una responsabilidad compartida pero diferenciada" en el seno del Comité. ${ }^{66}$

En Busan, el objetivo implícito del CAD era asociar a los emergentes, y es particular a China. ${ }^{67}$ La presencia india fue "débil", pues ningún representante oficial intervino en calidad de "vocero" o panelista en las sesiones de trabajo. Los delegados chinos abandonaron bruscamente la mesa de negociaciones al final del primer día, con el motivo de que su país había firmado la Declaración de París como beneficiario, y que China no estaba lista para respetar sus principios en calidad de donantes. Tras múltiples iniciativas diplomáticas (de Corea, del Departamento para el Desarrollo Internacional británico y del CAD) e importantes concesiones de fondo (las referencias a la inclusión de la gobernanza democrática, por ejemplo, no se integraron al documento), las autoridades accedieron a firmar el Documento de la Alianza de Busan, cosa que quizá el CAD interpretó como un gran éxito.

${ }^{63}$ Entrevista con Talaat Abdel-Malek, excopresidente del WP-EFF, vía skype, 26 de mayo de 2014.

${ }^{64}$ Runión de la WP-EFF, observaciones de campo, oCDE, París, 5 de octubre de 2011.

${ }^{65}$ Entrevista con Talaat Abdel-Malek, excopresidente del WP-EFF, vía skype, 26 de mayo de 2014.

${ }^{66}$ Gerardo Bracho Carpizo y García-Lopez, op. cit., pp. 68-69.

67 Conversación con Jonathan Glennie (Overseas Development Institute), durante la recepción de apertura del Foro de Busan, 30 de noviembre de 2011. 
Uno de los sucesos y resultados distintivos del Foro de Busan fue el fomento de una agenda global para la css y triangular, dirigida por Colombia e Indonesia, alimentada y respaldada por un bloque temático compuesto por una treintena de países y organizaciones del Sur. ${ }^{68}$ Uno de los objetivos de esta agenda para la OCDE es promover la cooperación institucional entre el CAD y las Naciones Unidas, en especial el PNUD y la Oficina de las Naciones Unidas para la Cooperación Sur-Sur, en el ámbito de la cooperación para el desarrollo. ${ }^{69}$ Sin embargo, Brasil, la India, China y Sudáfrica se suman a la iniciativa de dientes para afuera y no firman el Documento de Alianza de Busan más que con la condición de que el documento precise que "La naturaleza, modalidades y responsabilidades que se aplican a la cooperación Sur-Sur difieren de las que se aplican a la cooperación Norte-Sur [...] Los principios, compromisos y acciones acordadas en el documento final de Busan constituyen la referencia que podrá ser asumida voluntariamente por los socios de la cooperación Sur-Sur" (\$2). ${ }^{70}$

Tras impulsar el tema en el Foro de Busan y su éxito relativo, el CAD perdió su papel de palanca y análisis de la agenda para la css y triangular. Por solicitud de varios donantes emergentes, parece nacer una división del trabajo a partir de 2011: mientras que la CAD se ocupa exclusivamente de la cooperación triangular (es decir, que implica a un financiador del Norte, a un donador del Sur y a un país receptor), la css regresa a las Naciones Unidas. ${ }^{71} \mathrm{~A}$ diferencia de las esperanzas iniciales de la Secretaría, promover la

68 The South-South Opportunity, "South-South and Triangular Cooperation at the Busan HLF-4: Our Contribution to the Busan HLF4", 2011 (Blog), http:/ / www. southsouth.info/page/inputs-for-busan-hlf4, consultado el 10 de enero de 2012.

${ }^{69} \mathrm{El}$ CAD de la OCDE también publicó varios informes sobre la cooperación triangular que además de presentar el estado de esta forma de cooperación, concluyen sobre las oportunidades y la necesidad de fortalecer la cooperación triangular para el desarrollo. DCD/DAC, "What Can We Learn from a Survey of Actors Involved?", 2013 y DCD/DAC, "What is the Literature Telling Us?”, 2013.

${ }^{70}$ Busan Partnership for Effective Development Cooperation, $4^{\circ}$ Foro de Alto Nivel sobre Efectividad de la Ayuda, 29 de noviembre-1 diciembre de 2011.

${ }^{71}$ Entrevista con Talita Yamashiro Fordelone, consultora del Departamento de Cooperación de la ocDe, en Busan, el 1 de diciembre de 2011 y en París el 23 de abril de 2014. 
CSS y triangular no ha tendido el puente ni la entrada hacia los emergentes, finalmente, el tema desaparece de la agenda y de las actividades del CAD.

Varios factores explican la reticencia de Brasil, la India, China y Sudáfrica de comprometerse más a fondo en los trabajos del CAD sobre la eficacia de la ayuda. No permiten que "los restrinjan las reglas elaboradas por una organización [la OCDE] de la que no son miembros y a la que no contribuyen a moldear". ${ }^{72}$ Brasil y la India se preocupan por que no se los asocie con el CAD - una organización del Norte- pues se presentan como líderes o portavoces del Sur en otros terrenos multilaterales (como el G77). De igual forma, pretenden subrayar las especificidades y ventajas de la css frente a la cooperación Norte-Sur tradicional: ${ }^{73}$ principios de horizontalidad, beneficio mutuo, respeto de la soberanía de los beneficiarios. Un acercamiento con el CAD podría servir a la credibilidad de esta retórica. En fin, se rehúsan a dejarse arrastrar por los cooperantes occidentales y "compartir el peso" financiero de la ayuda, e insisten, a la manera de un representante chino en el Foro de Busan, en que la css constituye un complemento, y no un sustituto, de la AOD de los países ricos. ${ }^{74}$

Las diferentes estrategias que implementaron los emergentes del Sur conllevan un cambio de las prácticas hasta entonces vigentes en las instancias multilaterales. Las organizaciones internacionales se resisten tradicionalmente a la reforma o la redirección de sus formas de operación, pues estos cambios pueden atentar contra sus intereses y autoridad. Por lo tanto, en una primera etapa adoptan estrategias de resistencia, pero después consiguen adaptarse. ${ }^{75}$

72 Richard Woodward, "The Organisation for Economic Co-operation and Development: Meeting the Challenges of the Twenty-first Century", en Simon Lee y Steven Mcbride (comps.), Neo-Liberalism, State Power and Global Governance, Dordrecht, Springer Netherlands, 2007, p. 239.

73 DCD/DAC, "Non-DAC Countries and the Debate on Measuring post-2015 Development Finance”, Reunión DAC, 10 de febrero de 2014, p. 7.

${ }^{74}$ Charles Gore, op. cit. Este punto también se resalta en Silke Weinlich, "Emerging Powers at the UN: Ducking for Cover?", Third World Quarterly, vol. 35, núm. 10, 2014, pp. 1829-1844.

${ }^{75}$ Michael Barnett y Martha Finnemore, op. cit., p. 3. 


\section{Adaptaciones y ajustes institucionales al cambio}

Con respecto a la ONU y el CAD de la OCDE, el reto de asociar a los cooperantes emergentes del Sur no es menor, y la css suscita cada vez mayor interés. En el CAD, mientras que la crisis económica en Europa y Norteamérica podría acarrear la disminución de los montos de AOD disponibles, los donantes llamados tradicionales esperan conseguir que los nuevos donadores asuman una parte del financiamiento de la AOD. La css es un medio de conseguirlo, pero su legitimidad, eficacia y representatividad están en juego. La pertinencia de los trabajos del CAD podría reducirse si no lograran tomar en cuenta a los principales actores de la css, en especial la cooperación china, cuyos montos y efectos son considerables, en particular para el continente africano. ${ }^{76}$

Por lo tanto, la importancia y visibilidad crecientes de los donantes emergentes generan reacciones y evoluciones institucionales. Estas instituciones adaptan sus formas de operación internas y tienen en cuenta las quejas de los actores, como es el caso del PNUD; pero sucede lo mismo con las nuevas alianzas para el CAD de la OCDE.

\subsection{Las readaptaciones institucionales del PNUD}

Desde 2008, las trayectorias institucionales del PNUD y de la SU-SSC evolucionaron por el auge de las normas y prácticas de la cooperación Sur-Sur. El PNUD y la SU-SSC tuvieron que infringir sus reglas tradicionales de funcionamiento con respecto al fondo IBSA. ${ }^{77}$

En el caso del PNUD, esta readaptación institucional se manifiesta de forma general por una conversión de las modalidades de implementación de los programas de la css. ${ }^{78}$ Desde un punto de

${ }^{76}$ Entrevista con Alexandra Trzeciak-Duval, Jefa de la División de Política en la Dirección de Cooperación para el Desarrollo, oEcD, vía skype, 22 de julio de 2013.

77 James Mahoney y Kathleen Thelen, “A Theory of Gradual Institutional Change”, en James Mahoney, Kathleen Thelen (comps.), Explaining Institutional Change, Cambridge, Cambridge University Press, 2010, pp. 1-37.

78 Tales estrategias se ennumeran en el informe "An Agenda for Organizational 
vista operacional, el PNUD adopta un papel de facilitador en la transferencia de las competencias, del impulso de las capacidades en los sectores clave de la organización, que son la erradicación de la pobreza, la gobernanza democrática, el medio ambiente y el desarrollo duradero, así como la prevención de las crisis.

A nivel internacional, la readaptación institucional del PNUD desemboca en la revisión de las reglas y formas de operación mediante cambios de programas. ${ }^{79}$ La organización se ocupa cada vez más de la creación de centros temáticos, llamados "centros de excelencia", dedicados a la implementación de actividades de css junto con emergentes clave. Estos centros temáticos, cuyo objetivo es favorecer el fortalecimiento de las capacidades y la transferencia de las competencias entre países del Sur, gozan de una estructura híbrida con la asistencia técnica que provee el PNUD y los abundantes financiamientos de los gobiernos sede, pero también de los actores del sector privado, organizaciones no gubernamentales e incluso un aporte minoritario del PNUD. El primer centro temático, que se creó en 2009, el IPC-IG, se estableció en Brasil y apoya un conjunto de actividades de difusión del conocimiento, sobre todo los programas de transferencias condicionales y de protección social que tuvieron cierto éxito en Brasil, hacia otros países del Sur. ${ }^{80} \mathrm{En}$ Turquía, la India y Singapur se crearon centros similares ${ }^{81}$ El PNUD presenta estratégicamente estos centros diciendo que "permiten que las economías emergentes refuercen su liderazgo en su compromiso con la cooperación Sur-Sur". 82 El PNUD también firma alianzas estratégicas con varios países emergentes, entre ellos México

Change-Lifting UNDP Performance from Good to Great", UNDP, 2011, http://www.undp. org, consultado el 10 de octubre de 2014.

${ }^{79}$ Para un análisis de la readaptación de las instituciones y organizaciones internacionales a su ambiente, con el fin de enfrentarse a la crítica internacional y seguir existiendo, véase Michael Barnett y Martha Finnemore, op. cit., p. 43.

${ }^{80}$ Véase International Poverty Centre for Inclusive Growth, IPC-IG, www.ipcundp.org, consultado el 10 de octubre de 2013.

${ }^{81}$ International Centre for Private Sector in Development (Turquía); Global Centre for Public service Excellence (Singapur); International Centre for Human Development (India).

82 Evaluation of UNDP Contribution to South-South and Triangular Cooperation (2008-2011), undP, 2013 (Informe), pp. 32-33. 
(2011), Turquía (2011), Sudáfrica (2011), Brasil (2010) y China (2010) para "dar un nuevo impulso a la cooperación Sur-Sur y triangular" con estos socios clave.

En el plano intraorganizacional, el PNUD también reafirma de forma recurrente sus compromisos con el fomento de la cooperación Sur-Sur, prioridad explícita de las estrategias regionales y las estrategias-país. ${ }^{83}$ Estos compromisos se verbalizan cada vez con más frecuencia mediante declaraciones públicas de apoyo a los principios, aunque vagos, de la cooperación Sur-Sur en voz del administrador principal del PNUD en encuentros internacionales como la Conferencia de Alto Nivel para la Cooperación Sur-Sur de Nairobi en diciembre de 2009. ${ }^{84}$ Así, el PNUd opera un reposicionamiento estratégico en el seno del sistema de la onU como institución-referente de fomento de la agenda Sur-Sur, o de la cooperación Sur-Sur.

La percepción internacional de la institución se modifica progresivamente. ${ }^{85}$ Las estrategias de readaptación institucional van dando frutos en beneficio de la institución. Las demandas que hacen los emergentes en el PNUD para que éste asegure un papel de facilitador de sus actividades de cooperación Sur-Sur tienen un crecimiento progresivo. Desde 2009, las autoridades ministeriales de Brasil, China, Perú, Tailandia, Turquía y Mongolia apelan a la experiencia del PNUD para que ejecute sus proyectos en materia de desarrollo de las capacidades institucionales, en especial para las nuevas agencias de desarrollo, de expansión del conocimiento y de consejo estratégico para sus políticas públicas. Este compromiso creciente de los emergentes con el PNUD también es fuente de recursos financieros adicionales para la institución que padece un presupuesto relativamente débil, sobre todo para las actividades de css que inicialmente no representan más que el $0.5 \% .{ }^{86}$

83 Ibid., p. 29.

${ }^{84}$ Loc. cit.

85 Olivier Nay y Franck Petiteville, "Eléments pour une sociologie du changement dans les organisations internationales”, Critique Internationale, vol. 4, núm. 53, 2011, pp. 9-20.

${ }^{86}$ Evaluation of UNDP Contribution to South-South and Triangular Cooperation (2008-2011), pp. 31, 46. 
El posicionamiento del PNUD como socio en las decisiones de los programas de cooperación Sur-Sur de los financiadores emergentes también interviene en un contexto en que las autoridades de ciertos donantes, como Brasil, y específicamente el ministerio de Relaciones Exteriores y la Agencia Brasileña de Cooperación ( $\mathrm{ABC}$ ), también apelan a otras instituciones de la onU (la oms, la Unicef, el PMA, la FAO, la UNEP o la Unesco) ${ }^{87}$ Por lo tanto, el PNUd está en competencia con estas agencias, ${ }^{88}$ y su estatus de institución principal de fomento de la css se ve perpetuamente cuestionada.

Estos beneficios también se ilustran con el aumento del compromiso político de la institución con los emergentes: por ejemplo, se le otorgó el papel de institución facilitadora de la conferencia China-África para la reducción de la pobreza y el desarrollo de 2010, que reunió a veinte Estados africanos y nueve ministerios chinos. ${ }^{89}$ Los beneficios también son simbólicos, como indica el premio "Liderazgo visionario en la cooperación Sur-Sur y triangular" que la Conferencia de Alto Nivel sobre la Cooperación Sur-Sur de las Naciones Unidas concedió a la institución en 2012.90

Por lo tanto, las prácticas reformistas de los emergentes del Sur desembocan en readaptaciones institucionales estratégicas que actúan en ambos sentidos: mientras que los emergentes se sirven del multilateralismo para afirmarse y legitimarse, ${ }^{91}$ las instituciones multilaterales también se sirven de las dinámicas del surgimiento internacional para reposicionarse en la arquitectura institucional de la ayuda.

${ }^{87}$ Los detalles de estas contribuciones se precisan en el informe IPEA/ABC, op. cit.

${ }^{88}$ Olivier Nay y Franck Petiteville, op. cit.

89 Evaluation of UNDP Contribution to South-South and Triangular Cooperation (2008-2011), op. cit., p. 31.

90 "UNDP Awarded for Visionary Leadership in South-South and Triangular Cooperation”, http:/ /www.ssc.undp.org, consultado el 10 de octubre de 2014.

${ }^{91}$ Para un análisis de la función legitimadora de las instituciones internacionales con los actores estatales, véase Guillaume Devin, "Le multilatéralisme est-il fonctionnel?”, en Bertrand Badie y Guillaume Devin (comps.), Le multilatéralisme, nouvelles formes de l'action internationale, París, la Découverte, 2007, p. 238. 
3.2. La apertura y la alianza interinstitucionales: las tentativas de la alianza global para el desarrollo

Para responder las críticas de los emergentes sobre su déficit estructural de legitimidad, el CAD optó por una estrategia de apertura, volcada hacia afuera y no hacia adentro, orientada hacia otras instituciones multilaterales. Además de sus esfuerzos por facilitar la participación de los países no miembros del Sur, hizo una alianza estratégica con el PNUD en 2011, que se selló con la creación de la Alianza Global para la Cooperación Eficaz al Desarrollo. ${ }^{92}$ El objetivo para el CAD era unir su experiencia técnica con la representatividad de la agencia de la onU, encontrar un "equilibrio entre la eficacia y la representatividad, ${ }^{93}$ manteniendo la distancia para evitar las críticas y los retrocesos". 94

Sin embargo, el primer Foro de la Alianza Global, que se llevó a cabo en México en abril de 2014, confirmó que los esfuerzos del CAD para aliarse mejor e influir en los emergentes en el marco de la Agenda de París fracasaron rotundamente. Tres años después de su lanzamiento, la alianza con el PNUD no rindió los resultados esperados. Los representantes del PNUD afirmaron en México que la agencia participaba en la Alianza Global desde un punto de vista "técnico" sin poder representar "políticamente" al sistema de las Naciones Unidas. ${ }^{95} \mathrm{La}$ "Alianza" se percibió siempre como un proceso dirigido por el CAD y con fuerte influencia del Departamento para el Desarrollo Internacional británico (el representante de los donadores tradicionales en el comité directivo entre 2011 y 2013). 96

92 DCD/DAC/WP-EFF, "Proposed Mandate for the Global Partnership for Effective Development Co-operation: Proposal by the Post-Busan Interim Group", 28-29 de junio de 2012, Unesco, París, 11/06/2012, DCD/DAC/EFF, 7/Rev 1, 2012, p. 7.

93 DCD/DAC/WP-EFF, op. cit., p. 5.

${ }^{94}$ Entrevista con Talaat Abdel-Malek, excopresidente del WP-EFF, vía skype, 26 de mayo de 2014.

${ }^{95}$ Entrevista con Thomas Fues, economista, Jefe del Departamento de Formación, Instituto Alemán de Desarrollo, Bonn, 6 de mayo de 2014.

96 Entrevista con Christine Hackenesch, politóloga del Departamento de Cooperación para el Desarrollo bi y multilateral, Instituto Alemán de Desarrollo, 
La primera reunión de alto nivel de la Alianza Global en abril de 2014 desembocó en un desaire para el CAD. ${ }^{97}$ China informó en el último minuto que no participaría. Jonathan Glennie subraya que la India tampoco; la razón oficial son las elecciones previstas en el país unos días después. Sudáfrica no mandó delegación y Brasil precisó en las sesiones plenarias que no era parte de la Alianza Global; que se involucraría de manera informal en las negociaciones relativas al comunicado final. ${ }^{98}$ China y la India mostraron inquietud sobre la css, por un lado, y sobre la articulación entre la Alianza Global y los procesos preparatorios de la agenda post-2015 guiados por la onu, por el otro. Temen que el comunicado final sea considerado "elemento vinculante", aunque no todos los Estados miembros de la onu estaban presentes en México. ${ }^{99}$ Por lo tanto, los donantes emergentes afirman una vez más preferir que las cuestiones de la AOD se discutan en el marco de la ONU, sobre todo en el Foro de la Cooperación para el Desarrollo (FCD) de la ONU, creado en 2008 por iniciativa del G77 para "desafiar la supremacía del CAD" y con una función -la eficacia de la ayuda- muy cercana a la del comité especializado de la OCDE. ${ }^{100}$ Esta preferencia es ambigua, pues "los países emergentes [...] han sido prudentes en sus compromisos con el FDC [...] y [no han] aprovechado la oportunidad de hacer un foro pertinente o de utilizarlo para su propio interés". ${ }^{101}$

vía Skype, 29 de abril de 2014. Este punto también se señala en Talaat AbdelMalek, "The Global Partnership for Effective Development Cooperation: What Next for a Global Architecture?", The Current Column of 8 May 2014, Bonn, German Development Institute, 2014.

${ }^{97}$ Investigadores del Instituto Alemán de Desarrollo evocan un "setback" en Thomas Fues y Stephan Klingebiel, "Unrequited Love: What Is the Legacy of the First Global Partnership Summit?", The Current Column, 17 de abril de 2014.

98 Jonathan Glennie, "Development Partnership Conference: What Did We Learn?", The Guardian, 22 de abril de 2014.

99 "India, China Boycott High-Level Meeting on Global Partnership", Economic Times, 17 de abril de 2014.

${ }^{100}$ Rosalind Eyben, "Struggles in Paris: The DAC and the Purposes of Development Aid”, European Journal of Development Research, núm. 25, 2013, p. 88.

${ }^{101}$ Weinlich Silke, op. cit., pp. 10-11. 
Después, México, Brasil, China y la India asistieron a las reuniones del Grupo Interino Post-Busan (GIPB) como "observadores activos" y mostraron "un interés menor por el futuro de la alianza”. Brasil, China, la India, México y Sudáfrica no se unieron a su Comité Directivo; dejaron el lugar a Indonesia y Perú. ${ }^{102}$

Al mismo tiempo, el CAD -más allá del Grupo de Trabajo y de la Alianza Global- obtuvo algunos resultados sobresalientes con los emergentes. Por un lado, las vías de involucramiento con los no miembros del Sur, en particular los emergentes, se multiplicaron y trascendieron la Agenda de la eficacia de la ayuda desde el Foro de Busan. Los lazos tejidos a propósito del Grupo de Trabajo pudieron difundirse y aprovecharse en todos los trabajos de la Secretaría; y la apertura a los no miembros se volvió común. ${ }^{103}$

Por otra parte, cierta socialización en el lenguaje y métodos del $\mathrm{CAD}^{104}$ parece haber funcionado entre los representantes de los emergentes. En 2011, China publicó un Libro Blanco sobre la estrategia de la ayuda externa. Por supuesto que no responde al formato del CAD, pero sin duda resulta de la necesidad de las autoridades chinas de mejorar la comunicación y la transparencia de su política de cooperación y rompe con la práctica china que hasta entonces consistía en no salirse de los Ocho Principios de la ayuda que enunció Zhou Enlai en una visita en Somalia en 1964. En Busan, los representantes del Ministerio de Comercio chino evocaron su política de "ayuda", cosa que se negaban categóricamente a hacer hacía apenas unos años. En fin, China contribuyó con la última revisión de la ayuda en el CAD -y por lo tanto compartió información sobre sus prácticas como donante- y mostró un interés

102 Paulo Esteves y Manaíra Assunção, op. cit., p. 5.

103 Entrevista con Talita Yamashiro Fordelone, consultora del Departamento de Cooperación de la ocDe, en Busan, el 1 de diciembre de 2011 y en París el 23 de abril de 2014.

${ }^{104}$ Sobre el papel de las normas sociales y prácticas en las negociaciones multilaterales, véase, en relación al caso del Consejo de Seguridad de la onu, David Ambrosetti, Normes et rivalités diplomatiques à l'oNU. Le Conseil de sécurité en audience, Bruselas, P.I.E. Peter Lang, 2009, p. 349; y "L'humanitaire comme norme du discours au Conseil de sécurité: une pratique légitimatrice socialement sanctionnée”, Cultures et Conflits, vol. 4, núm. 60, 2005, pp. 39-62. 
creciente por la metodología del comité en materia de contabilización estadística y de gestión de proyectos de cooperación. ${ }^{105}$ En el mismo sentido, los miembros de la delegación brasileña usan desde 2011 la noción de "propiedad" - un pilar de la Agenda de Parísy desean ver surgir "buenas prácticas" de cooperación de las discusiones. En 2014, el CAD estableció trabajos y reuniones con Brasil, la India, China y Sudáfrica con miras a "desarrollar categorías y métodos estadísticos para incluir toda la información pertinente sobre las finanzas del desarrollo y facilitar la recopilación de datos entre todos los que cooperan con el desarrollo". Para esto, su Secretaría propone a los donadores emergentes identificar puntos de convergencia y una terminología común. A cambio, el CAD promete "ajustar sus sistemas estadísticos a sus necesidades" e incluirlos "en la gobernanza de su sistema de evaluación", lo que incluye darles un poder de decisión. ${ }^{106}$

Hay reflexiones en curso para identificar las posibilidades concretas de extender la influencia del CAD en el marco de la misión que definen sus textos fundadores y las posibilidades que brinda su presupuesto. La creación de una Secretaría para el Sur actualmente se estudia en el comité. ${ }^{107}$ Los miembros del comité constatan que "el mundo ha cambiado", pero también les interesa proteger el carácter exclusivo del comité. La Agenda de París ha producido pocos resultados, normas o compromisos suplementarios desde la Declaración de París. Algunos ven ahí el resultado de la estrategia de apertura -el creciente número de participantes conducirá a la proliferación de los intereses y a una difuminación de la agenda, e impulsará los compromisos fuertes por encima de un consenso débil- y dudan que la estructura de la Alianza Global, demasiado ligera, esté a la medida de redinamizar los trabajos del

\footnotetext{
105 Entrevista con Farida Tchaitchian Bena, Analista político conjunto ocDE/ UNDP, equipo de apoyo, París, 23 de abril de 2014.

106 DCD/DAC, "Non-DAC Countries and the Debate on Measuring Post-2015 Development Finance”, reunión DAC, 10 de febrero de 2014, DCD/DAC, 6, 2014, 2014, pp. 3-7.

${ }^{107}$ Entrevista con Jennifer Moreau, Asesora, Equipo de Gobernanza para el Desarrollo y la Paz, División de Alianza Global y Política, ocde-DCD, París, 27 de junio de 2014.
} 
CAD. ${ }^{108}$ También están conscientes de que la ayuda no es más que una fuente de financiamiento y de desarrollo -que además es secundaria- al lado de las contribuciones del sector privado, los impuestos, los flujos comerciales, las inversiones o los recursos naturales. No obstante, la AOD está en el centro del CAD y de su actividad, y toda innovación temática debe integrarse bajo el prisma de la estricta articulación de la ayuda.

\section{Conclusión}

Aunque los países emergentes se afirmen como financiadores de fondos y promotores de la css en la escena internacional, sus representantes dudan entre la creación de nuevas instancias de coordinación y la inversión diplomática y financiera en los terrenos multilaterales existentes. Entre estos últimos, no todos gozan de la misma legitimidad, representatividad y eficacia. Hasta ahora, los emergentes parecen privilegiar la participación en las instancias de la ONU. Aunque sus estrategias de participación en la ONU miren hacia la adaptación de las prácticas tradicionales de la institución y a aprovechar sus medios y su saber-hacer, consistieron claramente en deslegitimar y esquivar el CAD de la OCDE. La importancia y la visibilidad crecientes de los donantes emergentes del Sur presionaron a las instituciones multilaterales al mando de la gobernanza internacional de la AOD a adaptarse, y conllevaron una serie de cambios.

Los desarrollos más recientes no pusieron fin a los efectos de la competencia entre el CAD y el sistema de la onU en la gobernanza fragmentada de la AOD. Al contrario, atizan y renuevan los problemas. El papel del CAD siempre ha sido cuestionado, y su liderazgo en materia de producción de normas podría incluso haber disminuido desde la adopción de la Declaración de París en 2005. Thomas Fues y Stephan Klingebiel estiman que la Alianza Global "sigue siendo poco aceptada frente a los procesos de la onU en curso”,

108 Entrevista con Talaat Abdel-Malek, excopresidente del WP-EFF, vía skype, 26 de mayo de 2014. 
teniendo en cuenta los escasos apoyos y que la CAD debería de "confiar el control político [del proceso] a las Naciones Unidas". 109 El CAD difícilmente aceptará esta propuesta, pues inició e invirtió mucho en las cuestiones de eficacia de la APD y pretende conservar esta función de productor normativo. El Comité hace notar su valor añadido y sus ventajas comparativas con respecto al PNUD o al Foro de Cooperación para el Desarrollo: la experiencia y el conocimiento que alimenta su Secretaría, la capacidad de generar compromisos concretos (indicadores de progreso, calendarios) y de hacer que sus miembros y signatarios los respeten mediante mecanismos de revisión de pares o de evaluación continua. ${ }^{110}$

Por otra parte, estiman que transferir la agenda de la eficacia de la ayuda a las Naciones Unidas implicaría también politizarla, mientras que el CAD se jacta de tratarlas como cuestiones técnicas, y que los financiadores tradicionales no están interesados en delegar misiones a una institución en la que están peor representados. ${ }^{111}$

Los problemas de legitimidad, de colaboración y de división del trabajo se plantean con tanta mayor agudeza que deben resolverse en el contexto de la preparación de la agenda post OMD, que regresa a las Naciones Unidas. ${ }^{112}$ ¿Se deberían fusionar ambos procesos (Agenda de París y agenda post 2015)? Los emergentes se oponen y las Naciones Unidas no tendrían ningún interés en renunciar a su liderazgo; pero parece necesario un mínimo de coordinación para asegurar la coherencia y la realización de los objetivos respectivos de cada organización, y los objetivos generales que comparten.

\section{Traducción de Ana Inés Fernández Ayala}

109 Thomas Fues y Stephan Klingebiel, op. cit.

${ }^{110}$ Estos puntos se tratan a detalle en un precioso análisis comparado de la legitimidad entre el CAD y el FCD propuesto por Joren Verschaeve en "Is the Development Assistance Committee Still Calling the Tune in International Development? A Comparative Analysis of the Legitimacy of the OECD-DAC and the UN-DCF", op. cit.

111 Kim Soyeun y Simon Lightfoot, "Policy Arena. Does 'Dac-Ability' Really Matter? The Emergence Of Non-Dac Donors: Introduction to Policy Arena”, Journal of International Development, vol. 23, núm. 5, 2011, p. 717.

112 Entrevista con Thomas Fues, economista, Jefe del Departamento de Formación, Instituto Alemán de Desarrollo, Bonn, 6 de mayo de 2014. 


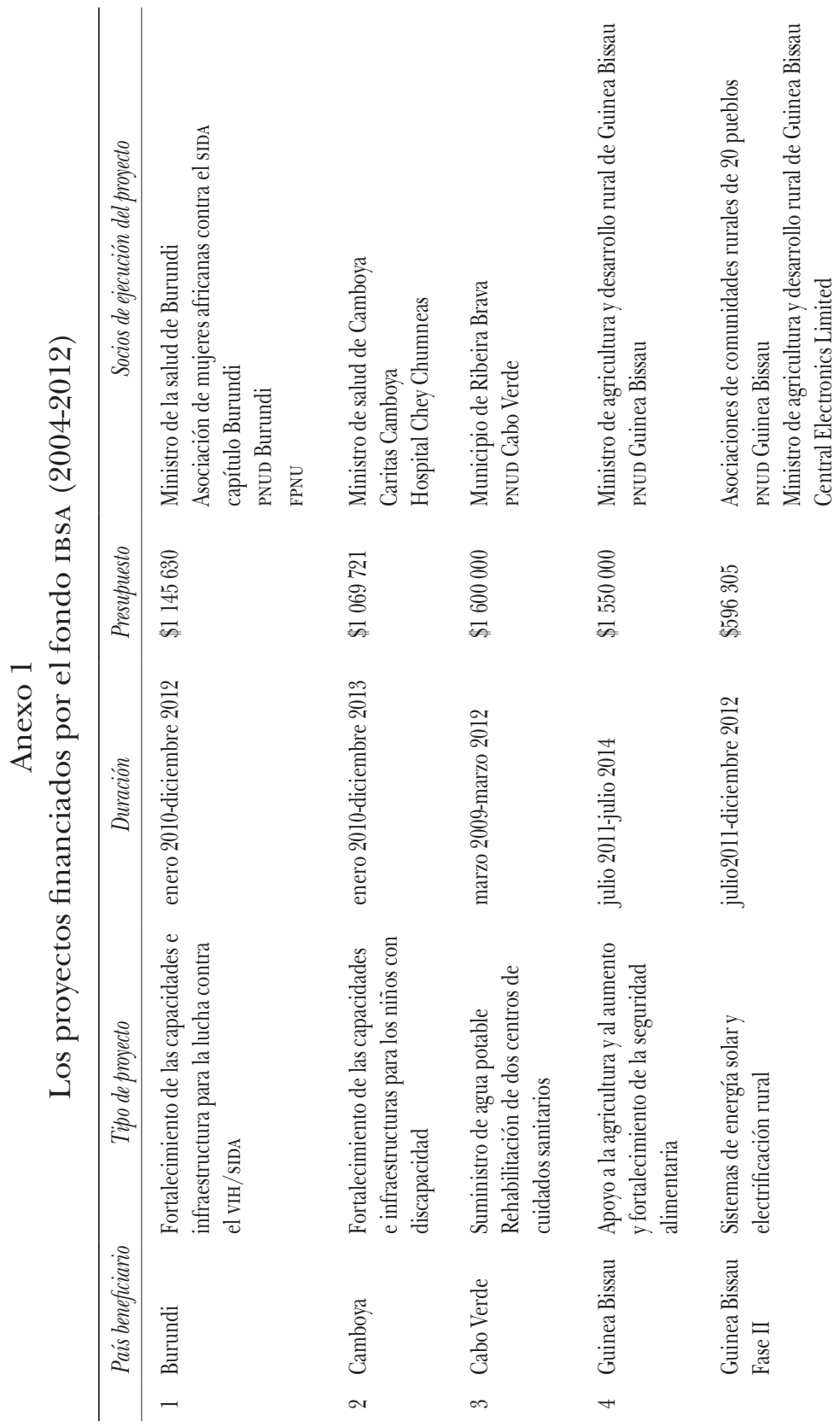




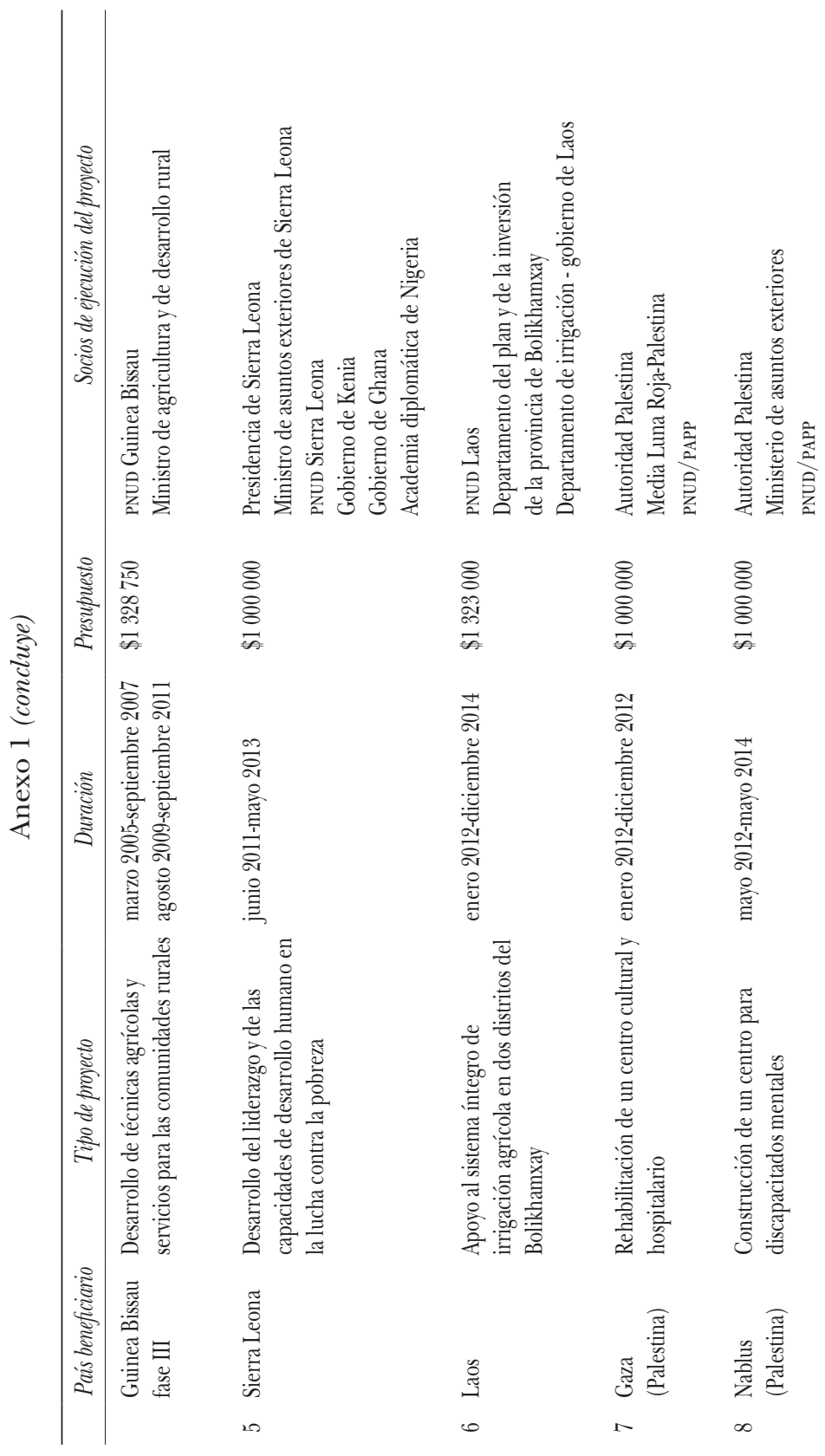




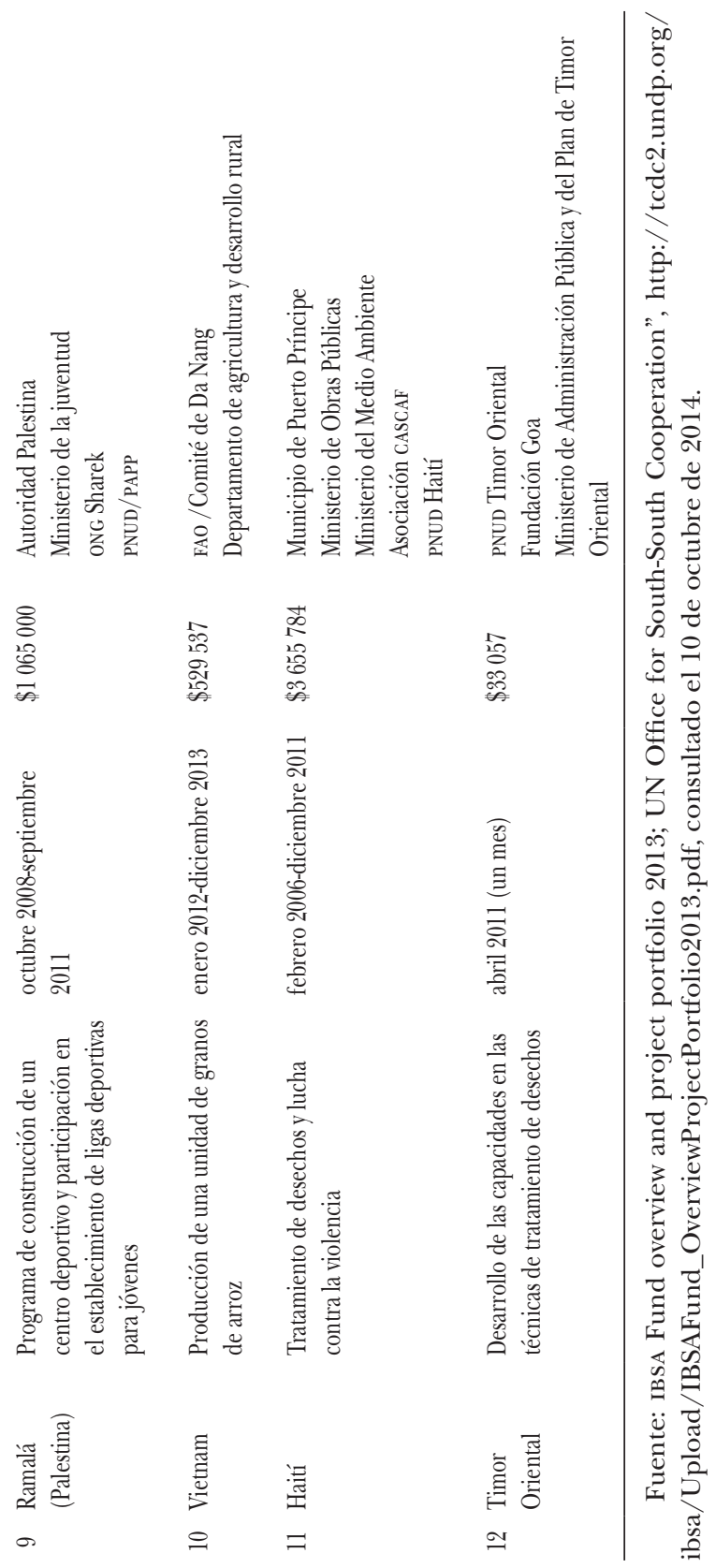




\section{BibLiOgRAFÍA}

United Nations Development Program, Evaluation of UNDP Contribution to South-South and Triangular Cooperation (2008-2011), informe, UNDP, 2013.

Ambrosetti, David, Normes et rivalités diplomatiques à l'oNU. Le Conseil de sécurité en audience, Bruselas, P.I.E. Peter Lang, 2009.

Ambrosetti, David, "L'humanitaire comme norme du discours au Conseil de sécurité: une pratique légitimatrice socialement sanctionnée", Cultures et Conflits, vol. 4, núm. 60, 2005, pp. 39-62.

Axelrod, Robert, Donnant-Donnant. Théorie du comportement coopératif, París, Odile Jacob, 1992.

—, The Evolution of Cooperation, Nueva York, Basic Books, 1984.

Barnett, Michael y Martha Finnemore, Rules for the World-International Organizations in Global Politics, Ithaca, Cornell University Press, 2004.

Bergamaschi, Isaline, "The DAC and the South: Strategies of Association and Participation", Presentación durante el Seminario Organisations Internationales, SciencesPo/CERI/GRAM, París, 5 de junio de 2014.

Besharati, Neissan Alessandro, "South African Development Partnership Agency (sAdpa): Strategic Aid or Development Packages for Africa?”, South African Institute of International Affairs, 2013 (Research Report núm. 12).

Bouchet, Nicolas, "La négociation multilatérale de l'aide aux Etats fragiles: constructions d'agendas et stratégies d'influence au Comité d'aide au développement de l'ocDE", Tesis de doctorado, Ciencia Política, IEP de Bordeaux, 2011.

Bracho Carpizo, Gerardo y Agustín Garcia-Lopez Loaeza, "México y el CAD de la OCDE: Una relación en construcción", Revista Española de Desarrollo y Cooperación, núm. 28, 2011, pp. 67-79.

Bull, Hedley, The Anarchical Society: A Study of Order in World Politics, Nueva York, Columbia University Press, 1977.

Charnoz, Olivier y Jean-Michel Severino, L'aide publique au développement, París, La Découverte, 2007.

Costa Leite, Iara et al., "Brazil's Engagement in International Development Cooperation: the State of the Debate", IDs, 2014 (Evidence Report núm. 59). 
De Renzio Paolo y Jurek Seifert, "South-South Cooperation and the Future of Development Assistance: Mapping Actors and Options", Third World Quarterly, vol. 35, núm. 10, 2014, pp. 1860-1875.

Devin, Guillaume, "Le multilatéralisme est-il fonctionnel ?”, en Bertrand Badie y Guillaume Devin (comps.), Le multilatéralisme, nouvelles formes de l'action internationale, París, La Découverte, 2007, pp. 145-165.

Dobry, Michel, Sociologie des crises politiques: la dynamique des mobilisations multisectorielles, París, Presses de Sciences Po, 2009.

Dufour, Patrice, "La Banque Mondiale et la lutte contre la pauvreté", Les Cahiers Français, núm. 5-6, 2001, pp. 56-65.

Esteves Paulo y Manaíra Assunção, "South-South Cooperation and the Battlefield of International Development: between the OECD and the UN", Third World Quarterly, vol. 35, núm. 10, 2014, pp. 1775-1790.

Eyben, Rosalind, "Struggles in Paris: The DAC and the Purposes of Development Aid”, European Journal of Development Research, núm. 25, 2013, pp. 78-91.

Eyben, Rosalind y Laura Savage, "Emerging and Submerging Powers: Imagined Geographies in the New Development Partnership at the Busan Fourth High Level Forum", The Journal of Development Studies, vol. 49, núm. 4, 2013, pp. 457-469.

Gabas, Jean-Jacques, "L'économie politique de la coopération pour le développement", Economies et Sociétés, vol. 8, núm. 35, 2000, pp. 65-86.

Gore Charles, "Introduction. The New Development Cooperation-Landscape: Actors, Approaches, Architecture”, Journal of International Development, vol. 25, núm. 6, 2013, pp. 769-786.

Hurrell Andrew, "Narratives of Emergence: Rising Powers and the End of the Third World?", Brazilian Journal of Political Economy, vol. 33, núm. 2, 2013, pp. 203-221.

Hurrell, Andrew, "Hegemony, Liberalism and Global Order: What Space for Would-Be Great Powers?”, International Affairs, vol. 82, núm. 1, 2006, pp. 1-19.

IPEA/ABC, "Brazilian Cooperation for International Development: 20052009”, 2011 (Informe).

Jaffrelot, Christophe (comp.), L'enjeu mondial. Les pays émergents, París, Presses de Sciences Po, 2008.

Kagia, Ruth (comp.), Balancing the Development Agenda: The Transformation 
of the World Bank under James D. Wolfensohn (1995-2002), Washington, D. C., The World Bank, 2005.

Keohane, Robert y Joseph Nye, Power and Interdependence, Nueva York, Longman, 2011.

Kothari, Uma, "From Colonial Administration to Development Studies: A Post-Colonial Critique of the History of Development Studies", en Uma Kothari (comp.), A Radical History of Development Studies: Individuals, Institutions and Ideologies, Nueva York, Zed Books, 2005, pp. 47-66.

Lesage, Dries y Thijs Van de Graaf (comps.), Rising Powers and Multilateral Institutions, Nueva York, Palgrave MacMillan, 2015.

Mahoney, James y Kathleen Thelen (comps.), Explaining Institutional Change, Cambridge, Cambridge University Press, 2010.

Nay, Olivier y Franck Petiteville, "Eléments pour une sociologie du changement dans les organisations internationales", Critique Internationale, vol. 4, núm. 53, 2011, pp. 9-20.

Quadir, Fahimul, "Rising Donors and the New Narrative of 'South-South' Cooperation: What Prospects for Changing the Landscape of Development Assistance Programs?”, Third World Quarterly, vol. 34, núm. 2, 2013, pp. 321-338.

Rist Gilbert, The History of Development: From Western Origins to Global Faith, Nueva York, Zed Books, 2002, p. 286.

Rosenau, James (comp.), Governance without Government: Order and Change in World Politics, Cambridge, Cambridge University Press, 1992.

Ruggie, John, "International Responses to Technology and Trends", International Organization, vol. 3, núm. 29, 1975, pp. 557-583.

Schulz, Nils-Sjard, "Development Agencies in BRICS and Beyond-Experiences and Next Steps", BRICs Policy Center, 2013 (BRICs Monitor).

Soulé-Kohndou Folashadé, "Les clubs de puissances émergentes: fonctions objectives et usages stratégiques- le cas du forum de dialogue ibas (Inde-Brésil-Afrique du Sud)", tesis de doctorado, Ciencia Política, Relaciones Internacionales, Instituto de Estudios Políticos de París, 2014.

Soyeun, Kim y Simon Lightfoot, "Policy Arena. Does 'Dac-Ability' Really Matter? The Emergence Of Non-Dac Donors: Introduction to Policy Arena”, Journal of International Development, vol. 23, núm. 5, 2011, pp. 711-721. 
Verschaeve, Joren, "Is the Development Assistance Committee Still Calling the Tune in International Development? A Comparative Analysis of the Legitimacy of the OECD-DAC and the UN-DCF", Presentacion durante la 8th Pan-European Conference on International Relations, Varsovia,18-21 de septiembre de 2013.

Vickers, Brendan, "Towards a New Aid Paradigm: South Africa as African Development Partner", Cambridge Review of International Affairs, vol. 25, núm. 4, 2012, pp. 535-556.

Weinlich, Silke, "Emerging Powers at the UN: Ducking for Cover?", Third World Quarterly, vol. 35, núm. 10, 2014, pp. 1829-1844.

Woods, Ngaire, The Globalizers: The IMF, the World Bank and their Borrowers, Ithaca, Londres, Cornell University Press, 2006.

Woodward Richard, "The Organisation for Economic Co-operation and Development: Meeting the Challenges of the Twenty-first Century", en Simon Lee and Steven Mcbride (comps.), Neo-Liberalism, State Power and Global Governance, Dordrecht, Springer Netherlands, 2007, pp. 231-244. 